\title{
Trends in heat treatment and surface engineering
}

\author{
Received: 26 October 2017 / Accepted: 12 June 2018
}

From June 26th to 29th 2017, was held in Nice Acropolis the 24th IFHTSE (International Federation for Heat Treatment and Surface Engineering) Congress. This annual European Conference on Heat Treatment and Surface Engineering was for this occasion combined with the A3TS (Association de Traitement Thermique et de Traitement de Surface) Congress.

Eighty-eight orals presentations and 36 posters were presented during this event that gathered more than 450 academics, engineers and researchers from industry. This event was an occasion to discuss and disseminate recent advances, innovations and developments in heat treatment and surface engineering.

The papers selected for this special issue of "Metallurgical Research \& Technology" were written to accompany the related conferences. They focus on several aspects of thermal treatment such as phase transformation, hardening, tempering, formation and stability of austenite. Methods for in situ analysis and modelling of engineered surfaces were also studied as well as the determination of mechanical properties by various methods like instrumented indentation, wear and tensile tests on materials with various microstructures.

Many thanks to the authors that have accepted to present their work in this journal.

Fabienne Delaunois, Francine Roudet, and Vitry Véronique Guest editors

Cite this article as: Fabienne Delaunois, Francine Roudet, Véronique Vitry, Trends in heat treatment and surface engineering, Metall. Res. Technol. 115, 401 (2018) 